American J. of Engineering and Applied Sciences 5 (1): 35-41, 2012

ISSN 1941-7020

(C) 2014 F.I. Abam et al., This open access article is distributed under a Creative Commons Attribution

(CC-BY) 3.0 license

\title{
Performance Analysis and \\ Components Irreversiblities of a (25 MW) Gas Turbine Power Plant Modeled with a Spray Cooler
}

\author{
Fidelis Ibiang Abam, Ikpi U. Ugot and Dodeye Ina Igbong \\ Department of Mechanical Engineering, Faculty of Engineering, \\ Cross River University of Technology, P. M. B 1123 Calabar, Nigeria
}

\begin{abstract}
In this study the effect of inlet air cooling system and components irreversibilities on the performance of an active $25 \mathrm{MW}$ gas turbine power plant was investigated. The objective of this study was to establish the potential benefits of improving the performance of the current gas turbine plant into a more advanced cycle with high efficiency and power output through inlet air cooling. Problem statement: The hypothesis was that the low performance of the gas turbine plant was caused by high ambient temperature, the use of spray cooler was adopted to bring the air condition temperature close to ISO condition. Approach: In this study, performance characteristics were determined for a set of actual operational conditions including ambient temperature, relative humidity, turbine inlet temperature and pressure ratio. Results: The results obtained show that the use of a spray cooler on the existing gas turbine cycle gives a better thermal efficiency and less irreversibility rate in the components system and the entire plant. The power output of the gas turbine plant with spray cooler was found to have increased by over $7 \%$, accompanied by $2.7 \%$ increase in machine efficiency with a reduction in specific fuel consumption of 2.05 and $10.03 \%$ increase in the energy of exhaust. Furthemore, a $0.32 \%$ reduction in the total irreversibility rate of the plant for the cooled cycle was obtained and a $0.39,0.29$ and $0.17 \%$ reduction in the irreversibility rate of compressor, turbine and combustion chamber respectively, were also obtained. Conclusion: The results show that retrofitting the existing gas turbine plant with inlet air cooling system gives a better system performance and may prove to be an attractive investment opportunity.
\end{abstract}

Key words: Gas Turbine (GT), Dry Bulb Temperature (DBT), Engineering Equation Software (EES), Specific Fuel Consumption (SFC), Relative Humidity (RH)

\section{INTRODUCTION}

Gas turbines are widely used for electricity generation in most countries of the world. They can be started and stopped easily allowing them to be brought into service as required to meet energy demand at peak conditions (Jaber et al., 2007). Because of natural gas availability and at low prices compared to distillate fuels, many countries of the world, example Nigeria utilizes large conventional gas turbines as based load units. The average efficiencies of gas turbine plants in the Nigerian energy utility sector over the past decade was in the range 27-30\% (Abam et al., 2011). The low efficiencies of the gas turbine plants are tired to many factors which include: operation mode, poor maintenance procedures, age of plant, discrinpancies in operating data, high ambient temperature and relative humidity. Power output and efficiency of a gas turbine plant depends largely on the condition of the compressor inlet air temperature (Cortes and William, 2003). The performance output during hot conditions is less compared to the performance at high air temperature and humid environment, so cooling the inlet air temperature to gas turbine, increases the air density, which enhances the mass flow rate of air and gives better power output (Jaber et al., 2007). Research has shown that gas turbine power output decreases by $18 \%$ for a $10^{\circ} \mathrm{C}$ increase in compressor inlet air temperature (Cortes and William, 2003). It has also been reported that high ambient temperature increases the turbine's heat rate resulting in gas turbine plants producing $25-35 \%$ less power in summer than winter at an average increase of $6 \%$ in fuel consumption (McCracker, 1991).

Many researchers have presented different methods of power augmentation (Landry and Sarian, 1994; Johnson, 1998) presented a discussion of the theory and operation of evaporative coolers for industrial gas

Corresponding Author: Fidelis Ibiang Abam, Department of Mechanical Engineering, Faculty of Engineering,

Cross River University of Technology, P. M. B 1123 Calabar, Nigeria 
turbine system applications. Ondryas et al. (2007) demonstrated the impact of using chillers at the air intake system to enhance gas turbine power output in a cogeneration plants they obtained over $20 \%$ increase in net power output. The study of (Elliot, 2001) shows that a $1 \%$ gain of the output power was obtained for every $1.6^{\circ} \mathrm{C}$ drop in compressor inlet air temperature using water chillers. Kolp et al. (2001) demonstrated the effect of various forms of inlet air cooling and supper charging of 40MW GE LM6000 gas turbine plant. Their results indicate that a $28^{\circ} \mathrm{C}$ reduction in the compressor inlet air temperature increased the net power output by 30\%. In addition, (Mercer, 2002) reported in his study that chillers utilizing thermal storage systems would increase the gas turbine power output by over $25 \%$ during peak periods. Similarly evaporative coolers gives an increase of about $10-15 \%$ power output, while water fogging a cooling technique will enhance power output by 10-20\% (Amell and Cadavid, 2002; Mohanty and Paloso, 1995).

Furthermore, With the rapid increase in electicity demand in Nigeria and the expected shortages in power supply due to delays in implimentation of the major power projects, retrofitting the existing Gas Turbine (GT) power plants in the power sector with inlet-air pre-cooling system is an attractive investment opportunity for the Power Holding Company of Nigeria (PHCN). This study studies the performance enhancement and modification of an active 25MW gas turbine plant (a grid-connected GT) operating at Delta Power Station in Nigeria using the prevailing climatic conditions. The performance of the proposed modified Bryton cycle is comparedwith base case condition (without inlet air cooling). The irreveribility rate in the componnets system of the gas turbine plant for the two scenario will be considered.

Gas turbine cycle parameters: Data used for the analysis are obtained from maintenance data sheet of $\mathrm{H}$ 25MW Hitachi single shaft turbine plant. The norminal performance data at ISO condition $\left(15^{\circ} \mathrm{C}\right.$ and $\left.60 \% \mathrm{RH}\right)$, power output 26.9MW, fuel Low Heating Value (LHV) $4699 \mathrm{~kJ} \mathrm{~kg}^{-1}$, rated revolution speed 7,280rpm, gas intake flow rate $88 \mathrm{~kg} \mathrm{sec}^{-1}$, exhaust gas temperature $555^{\circ} \mathrm{C}$, Pressure Ratio (PR) 14.7, compressor and turbine, 17 and 3 stages axial flow types.

Model description:The schematic diagram of the spray cooler and gas turbine plant are shown in Fig. 1 and 2. Cold water is sprayed into the dry atmospheric air entering the system with the help of injectors. The water spraying system is counter flow in evaporative cooler and modeled as an adiabatic saturator. The dry air mixes with water becoming saturated where the Dry Bulb Temperature (DBT) of inlet air reaches initial Wet Bulb Temperature (WBT).

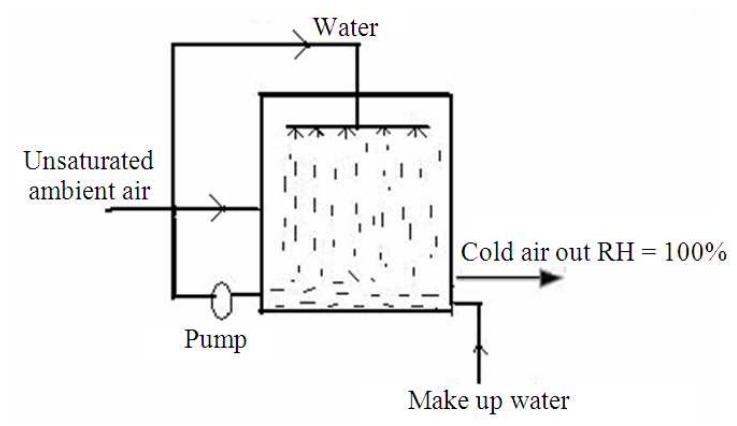

Fig. 1: Schematic diagram of spray cooler

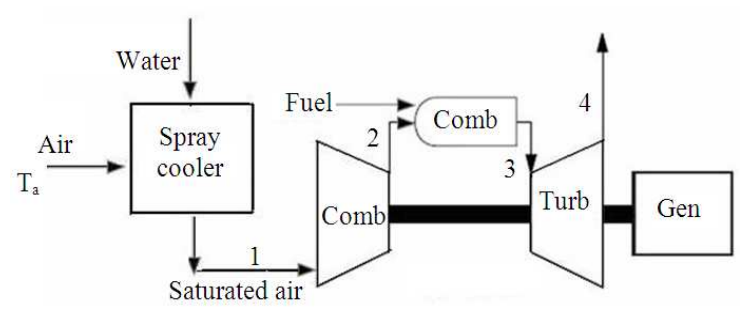

Fig. 2: Schematic diagram of gas turbine with spray cooler

It is assumed that the relative humidity of outlet air from the cooler will not exceed $100 \%$ despite the inlet air condition. The humidifying efficiency is assumed to be $100 \%$. The spray cooler lowers the ambient air tempertaure by $13^{\circ} \mathrm{C}$ for hot and dry ambient conditions, $50^{\circ} \mathrm{C}$ and $40 \%$ relative humidity and by $7.2^{\circ} \mathrm{C}$ for cold and humid conditions, $25^{\circ} \mathrm{C}$ and $50 \%$ relative humidity (Kumara et al., 2007). The gas turbine power plant models are developed on the following assumptions: (i) all components have adiabatic boundaries, (ii) plant performance at ISO conditions, (iii) the air and the combustion products are assume ideal characteristics, (iv) kinetic and potential components of energy are neglected and (v) the ambient conditions of temperature and pressure are $25^{\circ} \mathrm{C}$ and 1.013 bar Applying energy balance for the cooler in Fig. 1.

The heat interation between the ambient air and the saturated air is presented in Eq. 1 (Kumara et al., 2007):

$$
\begin{aligned}
& \mathrm{Cp}_{\mathrm{a}}\left(\mathrm{T}_{\mathrm{a}}-\mathrm{T}_{1}\right)=\left(\omega_{1}-\omega_{\mathrm{a}}\right) \mathrm{h}_{\mathrm{fg}} \\
& \omega=\frac{0.622 \mathrm{Pv}}{\mathrm{P}-\mathrm{Pv}}
\end{aligned}
$$

where, $\omega_{\mathrm{a}}$ and $\omega_{1}$ are humidity ratios before and after the saturation respectively. In general $\omega$ is related to the water vapour pressure at saturation as presented in Eq. 2 (Cengel and Boles, 2010), Pis pressure of air at 
intake and $\mathrm{Pv}$ is saturated pressure of water at intake. The cooler outlet temperature is obtained in Eq. 3 (Shanbghazani et al., 2008):

$\mathrm{T}_{1}=\mathrm{T}_{\mathrm{a}}-\left(\mathrm{T}_{\mathrm{a}}-\mathrm{T}_{\mathrm{wb}}\right) \times \varepsilon$

Where:

$\mathrm{T}_{\mathrm{a}}=$ Ambient temperature

$\mathrm{T}_{1}=$ Cooler outlet temperature

$\mathrm{T}_{\mathrm{wb}}=$ Wet bulb temperature

$\varepsilon \quad=$ Cooler efficiency

The working fluid passing through the compressor is assumed to be an ideal mixture of air and water vapour. The total enthalpy of atmospheric air is given below as in Eq. 4, (Cengel and Boles, 2010):

$\mathrm{h}=\mathrm{h}_{\mathrm{a}}+\omega \times \mathrm{h}_{\mathrm{v}} \cong \mathrm{C}_{\mathrm{p}}^{\mathrm{T}}+\omega \mathrm{h}_{\mathrm{g}}$

Where:

$\mathrm{h}_{\mathrm{a}}=$ Enthalpy of dry air

$\mathrm{h}_{\mathrm{v}}=$ The enthalpy of water vapour

The enthalpy of water vapour can be evaluated aproximately as in Eq. 5, Cengel and Boles (2010):

$\mathrm{h}_{\mathrm{v}}=2500.9+1.82 \times \mathrm{T}$

The total temperature of the fluid leaving the compressor having an isentropic efficiency $\eta_{C}$ can be evaluated using ideal gas relation obtained in Eq. 6 (Shanbghazani et al., 2008):

$\mathrm{T}_{02}=\mathrm{T}_{1}+\frac{\mathrm{T}_{2}-\mathrm{T}_{1}}{\eta_{\mathrm{C}}}=\mathrm{T}_{1}+\frac{\mathrm{T}_{1}}{\eta_{\mathrm{C}}}\left[\mathrm{r}_{\mathrm{p}}\left(\frac{\mathrm{k}-1}{\mathrm{k}}\right)-1\right]$

Where:

$\mathrm{r}_{\mathrm{p}}=$ Compressor ratio

$\mathrm{k}=$ Specific heat ratio

Similarly the total temperature leaving the turbine having an isentropic efficiency $\eta_{t}$ is given as Eq. 7:

$$
\mathrm{T}_{04}=\mathrm{T}_{3}-\eta_{\mathrm{T}}\left(\mathrm{T}_{3}-\mathrm{T}_{4}\right)
$$
Eq. 8:

The total mass flow rate of humid air is given as

$$
\dot{\mathrm{m}} \mathrm{ha}=\dot{\mathrm{m}} \mathrm{mda}+\omega \dot{\mathrm{m} d a}=(1+\omega) \dot{\mathrm{m} d a}
$$

where, mda and mha are mass flow rates of humid air and dry air. The compressor work is calculated from the mass flow rate and enthalpy change across the compressor Eq. 9:

$$
\dot{\mathrm{w}}_{\mathrm{c}}=\dot{\mathrm{m}}_{\mathrm{air}}(1+\omega) \times\left(\mathrm{C}_{\mathrm{pa}} \mathrm{T}_{02} \mathrm{C}_{\mathrm{pa}}-\mathrm{T}_{1}\right)+\omega\left(\mathrm{h}_{02}-\mathrm{h}_{1}\right)
$$

Similarly, the turbine work is obtained as Eq. 10:

$$
\begin{aligned}
& \dot{\mathrm{W}}_{\mathrm{T}}=\left(\dot{\mathrm{m}}_{\text {air }}+(1+\omega)+\dot{\mathrm{m}}_{\mathrm{f}}\right) \\
& \times\left(\mathrm{C}_{\mathrm{pg}} \mathrm{T}_{3}-\mathrm{C}_{\mathrm{pg}} \mathrm{T}_{04}\right)+\omega\left(\mathrm{h}_{3}-\mathrm{h}_{04}\right)
\end{aligned}
$$

The energy of exhaust gas $E_{G}$ is obtained as Eq. 11:

$$
\begin{aligned}
& \dot{\mathrm{E}}_{\mathrm{G}}=\left(\dot{\mathrm{m}}_{\mathrm{air}}+(1+\omega)+\dot{\mathrm{m}}_{\mathrm{f}}\right) \\
& \times\left(\mathrm{C}_{\mathrm{pg}} \mathrm{T}_{04}-\mathrm{C}_{\mathrm{pg}} \mathrm{T}_{1}\right)+\omega\left(\mathrm{h}_{04}-\mathrm{h}_{1}\right)
\end{aligned}
$$

The net power obtained from the gas turbine is Eq. 12:

$$
\dot{\mathrm{W}}_{\text {net }}=\dot{\mathrm{W}}_{\mathrm{T}}-\dot{\mathrm{W}}_{\mathrm{C}}
$$

The thermal efficiency of the gas turbine power plant is evaluated as Eq. 13:

$$
\eta_{\text {th }}=\frac{\dot{\mathrm{W}}_{\text {net }}}{\dot{\mathrm{m}}_{\mathrm{f}} \times \mathrm{LHV}}
$$

The specific fuel consumption is expressed in Eq. 14, (Shanbghazani et al., 2008). The Specific fuel consumption compares the ratio of the fuel used by an engine to a certain force such as the amount of power the engine produces. This is a very important economic criteria.

$$
\mathrm{Sfc}=\frac{3600 \times \dot{\mathrm{m}}_{\mathrm{f}}}{\dot{\mathrm{W}}_{\text {net }}} \mathrm{Kg} / \mathrm{KWh}
$$

Components irreversibilities: Equation 15 presents the steady state exergy balance equation for a control volume according to (Kotas, 1995):

$\dot{\mathrm{E} x}=\sum_{\mathrm{j}}\left(1-\frac{\mathrm{T}_{0}}{\mathrm{~T}_{\mathrm{j}}}\right) \dot{\mathrm{Q}}_{\mathrm{j}}+\dot{\mathrm{W}}_{\mathrm{CV}}+\sum_{\mathrm{i}} \mathrm{m}_{\mathrm{i}} \mathrm{e}_{\mathrm{i}}-\sum_{\mathrm{i}} \mathrm{m}_{\mathrm{e}} \mathrm{e}_{\mathrm{e}}$

The subscripts i.e., $\mathrm{j}$ and o refer to conditions at inlet and exits of control volume boundaries and reference state. The components irreversibility rates is derived from Eq. 15 written as Eq. 16: 


\section{Compressor:}

$$
\dot{\mathrm{I}}_{\mathrm{C}}=\dot{\mathrm{E}}_{\mathrm{X} 1}-\dot{\mathrm{E}}_{\mathrm{X} 2}+\dot{\mathrm{W}}_{\mathrm{C}}
$$

$\mathrm{W}_{\mathrm{c}}$ is the total power input rate to the compressor; $I_{c}$ is the total irreversibility rate in the compressor; $E_{x 1}$ is the exergy rate of the air and $E_{x 2}$ exergy outflow rate from the compressor unit.

Combustion chamber: The exergy flow rate in the combustion chamber is obtained from Eq. 15. In the combustion chamber, the shaft work is zero and Eq. 15 reduces to to Eq. 17 :

$\sum_{\mathrm{i}}\left(\dot{\mathrm{E}}_{\mathrm{xf}}\right) \mathrm{i}+\sum_{\mathrm{in}} \dot{\mathrm{E}}_{\mathrm{x}} \mathrm{c}_{2}=\sum_{\text {in }} \dot{\mathrm{E}}_{\mathrm{x}} \mathrm{cc}_{3}+\dot{\mathrm{I}}_{\mathrm{CC}}$

Where:

$\mathrm{I}_{\mathrm{CC}}=$ The combuction chamber irreversibilty.

$\mathrm{E}_{\mathrm{xf}}=$ Fuel exegy rate which is expressed in Eq. 18:

$$
\begin{aligned}
& \dot{\mathrm{E}}_{\mathrm{xf}}=\dot{\mathrm{E}}_{\mathrm{xph}}+\dot{\mathrm{E}}_{\mathrm{x}} \mathrm{chem}=\dot{\mathrm{m}} \mathrm{c}_{\mathrm{p}}^{\mathrm{h}} \\
& {\left[\left(\mathrm{T}_{3}-\mathrm{T}_{0}\right)-\mathrm{T}_{0} \mathrm{c}_{\mathrm{p}}^{\mathrm{s}} \ln \left(\frac{\mathrm{T}_{3}}{\mathrm{~T}_{0}}\right)\right]+\mathrm{RT}_{0} \ln } \\
& \left(\frac{\mathrm{P}_{2}}{\mathrm{P}_{0}}\right)+\sum_{\mathrm{i}} \mathrm{x}_{\mathrm{i}} \mathrm{e}_{\mathrm{io}}+\mathrm{RT}_{0} \sum_{\mathrm{i}} \ln \gamma_{\mathrm{i}} \mathrm{x}_{\mathrm{i}}
\end{aligned}
$$

$E_{x c h e m}$ is chemical exergy rate, $x_{i}$ is mole fraction of constituent's elements and $\mathrm{e}_{\mathrm{io}}$ is standard molar exergy of each constituent of the natural gas species.

$\mathrm{P}_{0}$ and $\mathrm{P}_{2}$ are the compressor inlet and exit pressures, respectively; $c_{p}^{h}$ and $c_{p}^{5}$ are mean molar isobaric heat capacity for evaluating enthalpy and entropy changes. They are expressed in Eq. 19 and 20:

$$
\mathrm{c}_{\mathrm{p}}^{\mathrm{h}}=\frac{1}{\mathrm{~T}-\mathrm{T}_{0}} \int_{\mathrm{T}_{0}}^{\mathrm{T}} \mathrm{c}_{\mathrm{p}}{ }^{-} \mathrm{dT}
$$

$\mathrm{C}_{\mathrm{p}}^{\mathrm{s}}=\frac{1}{\ln \left(\frac{\mathrm{T}}{\mathrm{T}_{0}}\right)} \int_{\mathrm{T}_{0}}^{\mathrm{T}} \mathrm{C}_{\mathrm{p}}^{-} \mathrm{dT}$

$\mathrm{c}_{\mathrm{p}}^{-}$is expressed or obtained in a polynomial form as a function of temperature as in Eq. 21 (Himmelblau and Riggs, 2012):

$c_{p}^{-}(T)=a+b^{2} T+c T^{2}+d T^{3}$

The values of a, b, c and $d$ are constant characteristics of the gas considered and obtained from standard tables.
Air and constituents of natural gas specific heats for $200 \mathrm{~K}<\mathrm{T}<800 \mathrm{~K}$ and $273 \mathrm{~K}<\mathrm{T}<1500 \mathrm{~K}$ respectively are given as in (Himmelblau and Riggs, 2012):

$$
\begin{aligned}
& \mathrm{C}_{\text {pair }}=28.09+0.1961 \times 10^{-2} \mathrm{~T} \\
& +0.4799 \times 10^{-5} \mathrm{~T}^{2}-1.965 \times 10^{-9} \mathrm{~T}^{3}
\end{aligned}
$$

For methane, ethane, propane e.t.c their specific heats are:

$$
\begin{aligned}
& \mathrm{C}_{\mathrm{p}} \mathrm{CH}_{4}=19.87+5.021 \times 10^{-2} \mathrm{~T} \\
& +0.366 \times 10^{-5} \mathrm{~T}^{2}-11 \times 10^{-9} \mathrm{~T}^{3} \\
& \mathrm{C}_{\mathrm{p}} \mathrm{C}_{2} \mathrm{H}_{6}=49.37+13.92 \times 10^{-2} \mathrm{~T} \\
& +5.816 \times 10^{-5} \mathrm{~T}^{2}-7.28 \times 10^{-9} \mathrm{~T}^{3} \\
& \mathrm{C}_{\mathrm{p}} \mathrm{C}_{3} \mathrm{H}_{8}=68.032+22.59 \times 10^{-2} \mathrm{~T} \\
& +71 \times 10^{-5} \mathrm{~T}^{2}-31 \times 10^{-9} \mathrm{~T}^{3}
\end{aligned}
$$

Turbine: The irreversibility rate in the turbine is obtained as in Eq. 22:

$$
\mathrm{i}_{\mathrm{T}}=\dot{\mathrm{m}}\left[\begin{array}{c}
\mathrm{T}_{0}\left(\mathrm{c}_{\mathrm{p}}^{\mathrm{s}} \ln \frac{\mathrm{T}_{3}}{\mathrm{~T}_{4}}-\mathrm{R} \ln \frac{\mathrm{P}_{3}}{\mathrm{P}_{4}}\right) \\
+\mathrm{c}_{\mathrm{p}}^{\mathrm{h}}\left(\mathrm{T}_{3}-\mathrm{T}_{4}\right)\left(1-\mathrm{\eta}_{\mathrm{T}}\right)
\end{array}\right]
$$

\section{MATERIALS AND METHODS}

Operating data for Gas turbine unit were collected from the daily turbine control $\log$ sheet for a period of two years. The daily average operating variables were calculated using MS Excel worksheets and the thermodynamic properties were determined using an Engineering Equation Software (EES). The analysis of the plant was divided into different control volumes and performance of the plant was estimated using component-wise modeling. Mass and energy conservation laws were applied to each component and the performance of the plant was determine for the simple system (without spray cooler) and for the cooled system (with spray cooler). The irreversibility rate and the efficiencies of the turbine components were evaluated employing Kotas exergy models. Results for the two scenario were compared.

\section{RESULTS}

The results of the effect of spray cooler on the performance of the gas turbine plant are presented. Figure 3 and 4 shows the variation in thermal efficiency with ambient temperature and power output for cooled and simple cycles at 60 and $100 \%$ Relative Humidity (RH). 


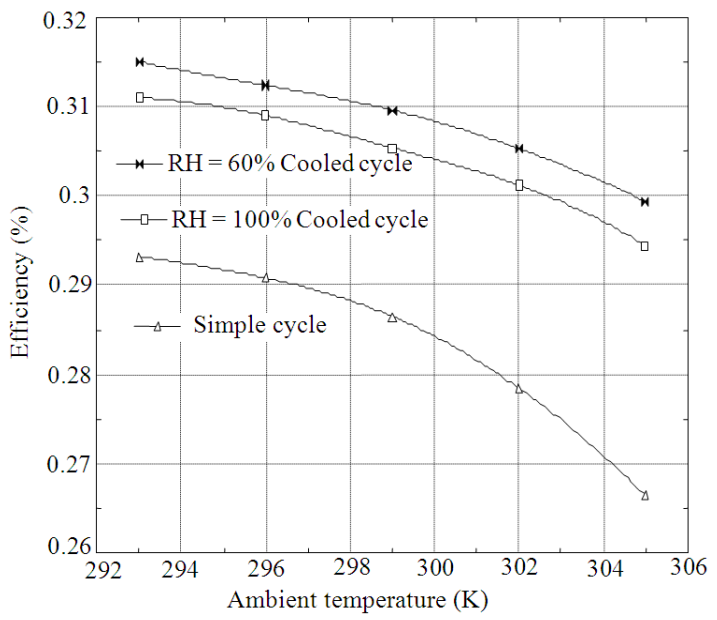

Fig. 3: Efficiency Vs ambient temperature for simple and cooled cycles

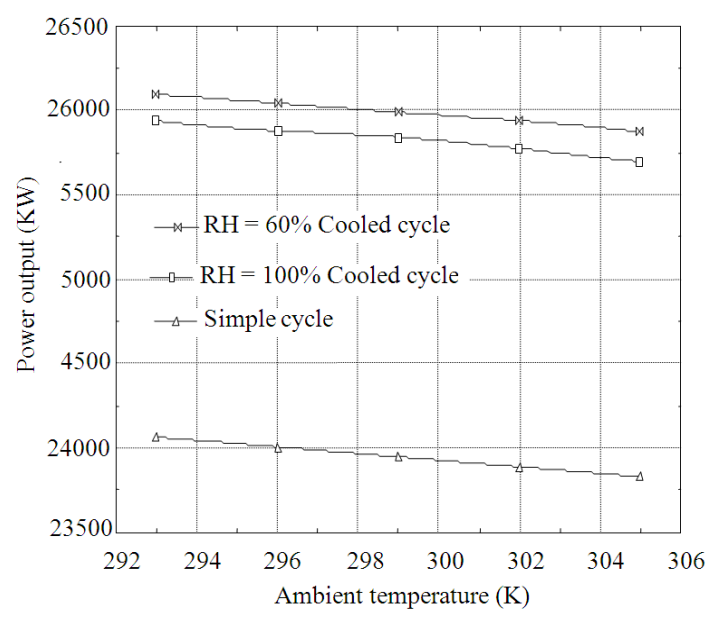

Fig. 4: Power output Vs ambient temperature for simple and cooled cycles

Table 1: Irreversibilty rates and component efficiencies for simple and cooled cycles

\begin{tabular}{lrrr}
\hline Components & Compressor & Combustion chamber & Turbine \\
\hline Simple cycle & & & \\
Irreversibilty rate (KW) & 11841.34 & 66368.76 & 26352.57 \\
Component efficiency (\%) & 70.20 & 30.67 & 60.35 \\
Cooled cycle & & & \\
Irreversibility rate (KW) & 11794.27 & 66256.64 & 26274.42 \\
Component efficiency (\%) & 72.37 & 33.54 & 62.44 \\
\hline
\end{tabular}

The variation in specific fuel consumption and the energy of exhaust with temperature for 60 anf $100 \%$ RH are shown in Fig. 5 and 6. While the effect of $20 \%$ increase in RH to power output is shown in Figure 7. The components irreversibilties and efficiencies of the gas turbine plant for the two cycles are presented in Table 1.

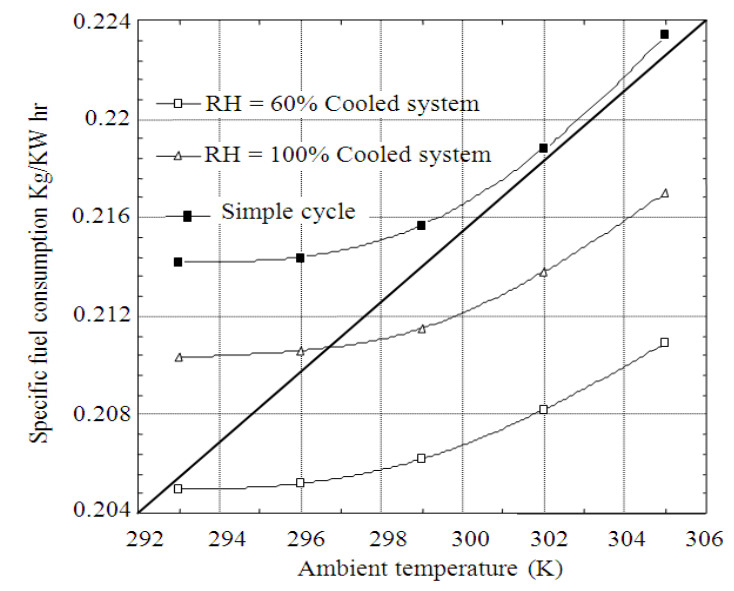

Fig. 5: Specific fuel consumption versus ambient temperature for simple and cooled cycles

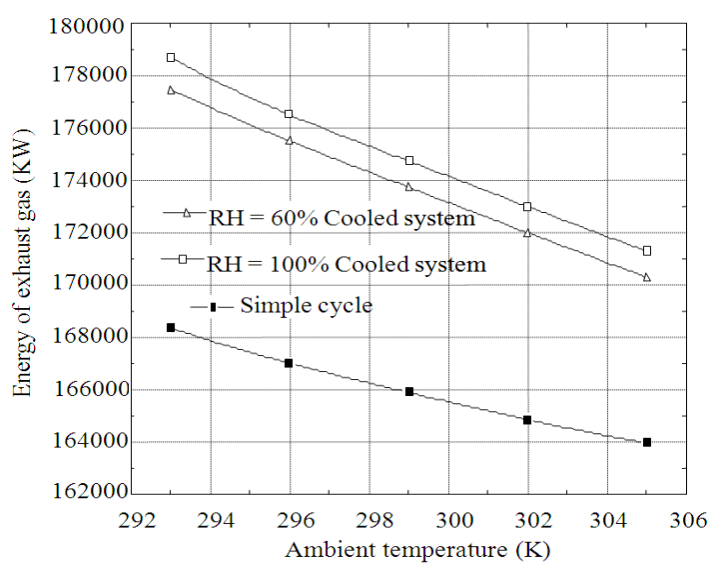

Fig. 6: Energy of exhaust versus ambient temperature for simple and cooled cycles

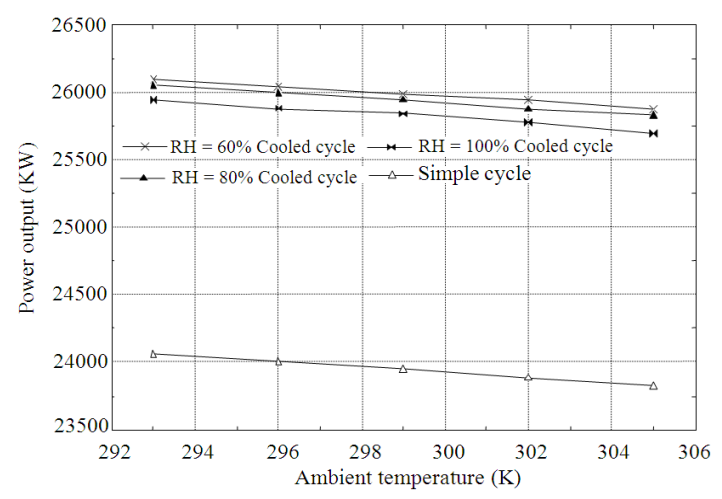

Fig. 7: Power output versus ambient temperature for $20 \%$ increase in relative humidity 


\section{DISCUSION}

The power output and the efficiency of the gas turbine cycle were calculated for different ambient air temperatures and for relative humidity of 60 and $100 \%$. Thermodynamic properties such as specific heats, humidity ratio of air, enthalpy of steam and combustion gasses were evaluated as a function of temperature, pressure, relative humidity by using an Engineering Equation Software (EES). Figure 3 and 4 shows the variation in thermal efficiency with ambient temperature and power output for cooled and simple cycles at 60 and $100 \%$ relative humidity. From the results a degree increase in ambient temperature lead to $0.79 \%$ drop in gas turbine rated power. For low ambient temperature of $23^{\circ} \mathrm{C}(296 \mathrm{~K})$ and Relative Humidity (RH) of $60 \%$ decreased to ISO standard design condition, the turbine output power increased by about $6 \%$ with a $2.1 \%$ increase in thermal efficiency. At high ambient temperature of $32^{\circ} \mathrm{C}(305 \mathrm{~K})$ and $60 \%$ relative humidity decreased to ISO standard condition, the power output increased by $7.95 \%$ with a $2.7 \%$ increase in thermal efficiency. The Specific Fuel Consumption (SFC) of gas turbine decreases as the ambient temperature increases as shown in Fig. 5. At low ambient temperature of $23^{\circ} \mathrm{C}$ and $60 \%$ relative humidity decreased to ISO standard design condition, the specific fuel consumption drops by $0.92 \%$ and at high ambient temperature of $32^{\circ} \mathrm{C}$ $(305 \mathrm{~K})$ and $60 \% \mathrm{RH}$ decreased to ISO standard condition the specific fuel consumption drops by $2.0 \%$. Figure 6 shows that at an ambient temperature of $23^{\circ} \mathrm{C}(296 \mathrm{~K})$ decrease to ISO standard condition, the energy of exhaust gases increases by $8.19 \%$ and at high ambient temperature of $33^{\circ} \mathrm{C}(306 \mathrm{~K})$ decrease to ISO standard condition, the energy of exhaust gases increases by $10.03 \%$. This means that lowering the inlet air temperature will lead to an increase in the exhaust gas flow rate with more heat recovered from the exhaust gases (Karim, 2008). Further increase in Relative Humidity (RH) by $20 \%$ as shown in Fig. 7 results to a decrease in power output of about $0.32 \%$ accompanied by a corresponding drop of $0.32 \%$ in thermal efficiency and about $0.33 \%$ increase in specific fuel consumption. This trend is in agreement with the results obtained by (Karim, 2008). Better performance of the gas turbine plant can be obtained as shown from the results when the operating conditions are brought close to ISO conditions.

Table 1 presents the irreversibility rate and efficiencies of components system of the gas turbine plant. The total irreversibility rate for the simple cycle is $155275.91 \mathrm{KW}$ while for the cooled cycle is $154786.45 \mathrm{KW}$. The result shows that a drop in ambient temperature caused a $0.32 \%$ reduction in the total irreversibility rate of the plant. Similarly, a drop in ambient temperature leads to $0.39,0.29$ and $0.17 \%$ decrease in irreversibility rate of compressor, turbine and combustion chamber respectively. The combustion chamber has the lowest efficiency due to large irreversibilities resulting from the differences between flame and combustion fuel. The performamce parameters for the cooled cycle at all values of ambient temperature improves the gas turbine system. The results also show a reduction in the rate of irreversibility in gas turbine components for cooled cycle in Table 1, where components efficiencies were improved culminating to a low thermal discharge index of 3.24 . Thermal Discharge Index (TDI) is the total number of thermal energy units discharged to the environment for every unit of electrical energy produced by the plant. It is completely dependent on thermal efficiency (Culp, 1979). Low value of TDI conotes better system performance.

\section{CONCLUSION}

The performance of spray cooler is dependent on ambient temperature and humidity. The system works efficiently during dry and hot climatic conditions prevalent in some locations in Nigeria. The results obtained show that, the use of an inlet air cooling system as a measure for system enhancement was found to increase the power output of the gas turbine by over $7 \%$, accompanied by $2.7 \%$ increase in machine efficiency. A drop in specific fuel consumption of 2.0 and $10.03 \%$ increase in energy of exhaust were observed. The irreversibility rate is less for the cooled cycle with improvement in thermal efficiency which is due to less entropy generation. However, comparing the cooled cycle and the simple cycle it was observed that for any ambient temperature and relative humidity, the cooled cycle improves all the performance indices of the gas turbine plant. The payback period for the spray cooler is between 4-5 years. Water needed for operation of sprayer may be a serious constraint in some areas, but condensing water from the exhaust system is one method for recovering partially the make up water for spray cooler especially in extreme dry climates., in order to select a particular cooling technique for adoption in Nigerian energy utility sector, research including system performance and economic analysis of the cooling methods will appear to be merited. 


\section{REFERENCES}

Abam, F.I., I.U. Ugot and D.I. Igbong, 2011. Thermodynamic assessment of grid-based gas turbine power plants in Nigeria. J. Emerg. Trends Eng. Applied Sci., 2: 1026-1033.

Amell, A.A. and F.J. Cadavid, 2002. Influence of the relative humidity on the air cooling thermal load in gas turbine power plant. Applied Thermal Eng., 22: 1529-1533. DOI: 10.1016/S1359-4311(02)00063-7

Cengel, Y.A. and M.A. Boles, 2010. Thermodynamics: An Engineering Approach. 7th Edn., McGraw-Hill, New York, ISBN-10: 9780073529325 pp: 1024.

Cortes, C.R. and D.F. Williams, 2003. Gas turbine inlet air cooling techniques: An overview of current technologies. Power-Gen International, Las Vegas Neva, USA.

Culp, A.W., 1979. Principles of Energy Conversion. 1st Edn., McGraw-Hill, New York, ISBN-10: 0070148929 pp: 499.

Elliot, J., 2001. Chilled air takes weather out of equation. Diesel and Gas Turbine World Wide Gas Turbine Publications, USA.

Himmelblau, D.M. and J.B. Riggs, 2012. Basic Principles and Calculations in Chemical Engineering. 8th Edn., Prentice Hall London, New Jersi, ISBN: 9780132346603, pp: 752.

Jaber, Q.M., J.O. Jaber and M.A. Khawaldah, 2007. Assessment of power augmentation from gas turbine power plants using different inlet air cooling systems. J. Mech. Ind. Eng., 1: 7-15.

Johnson, R.S., 1998. The theory and operation of evaporative coolers for industrial gas turbine installations. The American Society of Mechanical Engineers, New York.

Karim, Z.A.A., 2008. Effect of inlet air cooling on gas turbine performance. Proceedings of the International Conference on Mechanical and Manufacturing Engineering, (MME' 08), Johor Bahru Malaysia.
Kolp, D.A., W.M. Flye and H.A. Guidotti, 2001. Advantages of air conditioning and supercharging an LM6000 gas turbine Inlet. J. Eng. Gas Turbine Power Trans. ASME, 117: 513-527. DOI: $10.1115 / 1.2814125$

Kotas, T.J., 1995. The Exergy Method of Thermal Plant Analysis. 1st Edn., Krieger Pub., Malabar, FL., ISBN-10: 0894649418, pp: 328.

Kumara, N.R., K.R. Krishnab and A.V.S.R. Rajuc, 2007. Performance improvement and exergy analysis of gas turbine power plant with alternative regenerator and intake air cooling. Energy Eng., 104: 36-53. DOI: 10.1080/01998590709509498

Landry, M. and S. Sairan, 1994. The capacity augmentation of an 18MW gas turbine using ice Harvesting Thermal Energy Storage (TESTIAC). Power-Gen Asia, 94, Henry Vogt Machine, USA and Tenaga National Research and Development Sdn. Bhd. Malaysia.

McCracker, C.D., 1991. Off-peak air-condition: Major energy save. ASHRAE J., 2: 12-13.

Mercer, M., 2002. One stop shop for inlet cooling systems diesel and gas turbine. Worldwide Gas Turbine Publications, USA.

Mohanty, B. and J. Paloso Jr., 1995. Enhancing gas turbine performance by intake air cooling using an absorption chiller. Heat Recovery Syst. CHP, 15: 41-45. DOI: 10.1016/0890-4332(95)90036-5

Ondryas, I.S., D.A. Wilson, M. Kawamoto and G.L. Haub, 2007. Options in gas turbine power augmentation using inlet air chilling. Eng. Gas Turbine Power Trans. ASME, 113: 203-211. DOI: 10.1115/1.2906546

Shanbghazani, M., S. Khalilarya and I. Mizaee, 2008. Exergy analysis of a gas turbine system with evaporative cooling at compressor inlet. Int. J. Exergy, 5: 309-325. DOI: 10.1504/IJEX.2008.018113 